\title{
La era de los satélites
}

\author{
Julio Estremadoyro Alegre \\ Departamento Académico de Comunicación Social
}

Desde la época de las cavernas, el hombre trató de que su comunicación alcanzara la mayor distancia para llegar al mayor número de personas, en el menor tiempo posible y con una calidad en sus mensajes que fuera de tal claridad y perfección que permitiera entenderlos sin duda alguna. Un millón de años tardó el ser humano en crear la tecnología necesaria. Todo comenzó en el siglo XIX con el descubrimiento de la electricidad. Pronto vino su primera utilización con el telégrafo, luego con el teléfono. En el siglo XX, el ser humano inventó la radio y la transmisión aérea. Enseguida le tocó el turno a la emisión asombrosa de la imagen: la TV. Entonces surge la revolución espacial: los Satélites de Comunicaciones. Con Pelids] seodteanzaran tas geandes.metas de la comunicación humana.

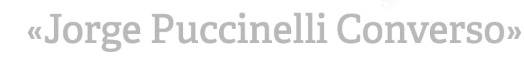

Las primeras hazañas: el hombre en el espacio

IF 1 día viernes 4 de octubre de 1957 la entonces Unión Soviética

14 sorprendió al mundo al poner por primera vez en la historia un satélite orbital, que con su "bip... bip" inició la era espacial. El Sputnik $I$ era una esfera de $58 \mathrm{~cm}$. de diámetro y un peso de $83.6 \mathrm{~kg}$. A la velocidad de 24,500 kilómetros por hora podía dar una revolución completa a la tierra en 95 minutos. Con ello se abrió una nueva y portentosa etapa en la historia de la

Letras (Lima), 99-100, 2000: 89-102 
civilización. Fue el símbolo de la Era espacial y se convirtió en uno de los más significativos vehículos de una revolución científica y tecnológica que abrió las puertas del futuro.

Un mes más tarde, el 3 de noviembre, la Unión Soviética colocó en órbita una nuevo Sputnik que transportó una serie de instrumentos científicos y a la perrita Laika, el primer ser vivo en viajar en un satélite artificial. El experimento proporcionó, en los seis días que duró el viaje espacial, una serie de importantes datos científicos. El más importante: que un ser vivo podía sobrevivir a la ingravidez.

Los éxitos soviéticos obligaron a los norteamericanos a acelerar sus planes espaciales. Es así que el $1^{\circ}$ de febrero de 1958 lanzaron al espacio, mediante un cohete Júpiter $C$, el primer satélite artificial de los Estados Unidos. Se llamó el Explorer I, con un peso de 14 kilos.

Luego siguieron una serie de lanzamientos, tanto de los soviéticos como de los norteamericanos, con sus satélites Lunik y Pionner, respectivamente. Los soviéticos lograron un nuevo e importante triunfo en la carrera especial con el Lunik III, el 4 de octubre de 1959, que consiguió orbitar la Luna y obtener las primeras fotografías de la cara oculta de nuestro satélite, jamás vista por el ojo humano.

El primer hombre en el espacio fue el mayor Youri Gagarine, quien el 12 de abril de 1961, ớbitơ la tierra en el Vostok ${ }^{1}$, describiendo una órbita elíptica, a una distancia de la Tierra que variaba entre los 175 y 327 km.

Pocos meses después el astronauta norteamericano John Glenn, en una cápsula Mercury, orbitó nuestra planeta, a una altura máxima de 260 km.

Luego siguieron una serie de vuelos espaciales, entre ellos el de la primera astronauta, la soviética Valentina Terechkova y unos paseos fuera de la cápsula Géminis $I V$ a $161 \mathrm{~km}$. de la Tierra, hasta llegar al momento en que el hombre visitó la Luna.

Antes ocurrió una tragedia el 27 de enero de 1967, cuando murieron tres astronautas norteamericano, durante un ejercicio preparatorio, al incendiarse la cápsula en la qùe se encontraban practicando. 
El momento culminante llegó el 18 de julio de 1969, cuando, desde Cabo Kennedy fue lanzado el Apolo XI, con los astronautas Neil Armstrong, Edwin Aldrin y Michael Collins, quien se quedaría a bordo de la nave madre orbitando la Luna, en espera del regreso de sus dos colegas quienes descendieron en el módulo lunar el 21 de julio. A las 3 y 56 de la tarde, hora de Lima, Neil Armstrong pisó el suelo lunar con su célebre frase: "Un pequeño paso para el hombre, un gran salto para la Humanidad".

El satélite artificial es un artefacto de compleja tecnología que, lanzado al espacio, se sitúa en órbita terrestre de circunvalación (girando alrededor del planeta) o geoestacionarias (que permanece fijo sobre la línea ecuatorial) para desempeñar múltiples tareas.

De acuerdo con su función, los satélites pueden ser de comunicaciones, de observación y astronómicos. Todos ellos, independientemente de los dispositivos específicos que lleven para su cometido, constan de un panel de células fotoeléctricas, que convierten la luz solar en energía eléctrica, antenas de transmisión e impulsores para hacerlos girar y corregir su alineación orbital, y pequeñas computadoras.

Desde que Estados Unidos lanzara en 1962 el Telstar, primer satélite de comunicaciones, éstos dieron un espectacular salto hacia adelante.

\section{Biblioteca de Letras}

\section{Los satélites de comunteaciones:Cinfolmación sinf fronteras}

En 1965 fue lanzado por la Organización Internacional de Telecomunicaciones por Satélite (INTELSAT) el Pájaro madrugador (Early Bird), el primer satélite operacional de comunicaciones, que no solo superó la eficiencia de los servicios de comunicaciones mundiales ya conocidos, sino que fue el inicio de la era de las transmisiones de televisión "en vivo".

Con los satélites, las comunicaciones alcanzan su punto culminante en el proceso de desarrollo de emisión y recepción de señales radioeléctricas.

El satélite puede recibir señales telefónicas, telegráficas y de televisión subidas desde una estación en tierra, y, luego de ampliarlas, las baja a otras estaciones que, en su turno, las envía por torres de microondas o cable coaxial hasta los usuarios finales. El satélite sustituye, para decirlo de alguna manera, 
a una gigantesca torre de microondas en el cielo.

Los satélites están construidos con un sistema de celdas que transforman la energía solar en energía eléctrica, necesaria para la operatividad de sus sistemas. Están equipadas con antenas parabólicas para la recepción de señales que vienen de tierra que luego retransmite en un "haz concentrado" a otros puntos del planeta.

Los satélites de comunicaciones son colocados en la llamada órbita geoestacionaria, es decir a aproximadamente $36,000 \mathrm{~km}$. de distancia de la Tierra, sobre la línea del Ecuador. Por ello, a estos satélites también se les conoce como satélites geoestacionarios. En esta posición un satélite cubre la tercera parte del globo terráqueo y tres satélites aseguran un servicio mundial.

Los satélites geoestacionarios dan vuelta sobre su propio eje, a la vez que giran a la misma velocidad y en la misma dirección de la Tierra. De tal manera que parecen fijos con relación a las estaciones terrenas, permitiendo el enfoque de las antenas parabólicas en línea recta. Por ello se les conoce también como satélites sincrónicos o geosincrónicos.

El costo de un satélite de comunicaciones varia entre 85 y 210 millones de dólares.

La órbita geoestacionaria permite hastâ 180 satélites. Es decir un satélite cada 2 grados. En la actualidad las posiclones estañ eàsi totalmente adjudicadas.

Los satélites de comunicaciones tienen una vida útil limitada, debido al desgaste del combustible que requieren los cohetes estabilizadores de la ubicación del satélite (norte-sur). En la actualidad, se aplica la técnica que permite al satélite flotar naturalmente o a la deriva en el espacio con lo que dura más su vida operativa con sus consecuencias en el menor costo de los servicios.

Existen satélites de Consorcios Internacionales (Intelsat, Interspunik y Agencia Espacial Europea, ente otros); Satélites Nacionales (lo tienen Estados Unidos, Unión Soviética, Canadá, Indonesia, Japón, China, India, México y Brasil); Satélites Privados (Panamsat); y Satélites Militares (para comunicaciones secretas y codificadas). 
Los satélites de Intelsat tienen hasta 24 transpondedores. Y hasta antes de la digitalización y compresión de la señal, podían transmitir hasta 12 mil llamadas telefónicas simultáneamente o 24 emisiones de televisión.

También hay satélites de comunicaciones elípticos, no fijos en el espacio, ya que se desplazan constantemente en una órbita irregular con un apogeo $\mathrm{y}$ un perigeo.

Para captar la señal de estos satélites son necesarias antenas rastreadoras, es decir con un movimiento prefijado sobre su eje para seguir el desplazamiento de estos artefactos. El uso de este tipo de satélites conforma el sistema de comunicaciones nacionales de los países que conformaban la antigua Unión Soviética, sobre todo Rusia con un territorio tan extenso, ubicado en lejanas latitudes septentrionales. En la actualidad, centenares de estos satélites conformarán una gigantesca red de comunicaciones celulares en el mundo entero.

A más de 40 años del comienzo de la era espacial, los adelantos presenciados en el desarrollo de esta tecnología son cada vez más significativos y los beneficios prácticos de la utilización del espacio ultraterrestre han aumentado a pasos agigantados, sobre todo con la digitalización y compresión de las señales, que ha permitido multiplicar la capacidad de transmisiones, con una calidad de imagen y sonido realmente sorprendentes.

Hay que precisar quelel asombrosê y fantástico desarrollo de Internet no hubiera sido posibleschela existendià de losesatelites de comunicaciones. $\mathrm{La}$ Red se basó fundamentalmente en contactos telefónicos, que los servidores de cada localidad los levantan a los satélites y, luego, en una operación realizada a 300 mil kilómetros por segundo -la velocidad de la luz-, son bajados y subidos a estaciones y satélites, hasta llegar a los respectivos destinos.

Un gran organismo mundial regula el sistema de los satélites de comunicaciones. Se trata de Unión Internacional de Telecomunicaciones (UIT).

Satélites de comunicación directa: recepción hogareña

Una de los mayores avances del satélite de comunicaciones es el denominado Satélite de Radiodifusión Directa para TV. 
Se ha superado la era del satélite distribuidor de baja potencia, que transmite programas a través del filtro de una televisora o un sistema de cable, a la del Satélite de Radiodifusión Directa (SRD) con una señal de mayor potencia que puede llegar directamente a cada hogar, dotado de una pequeña antena receptora de unos 60 centímetros de diámetro.

Con el sistema SRD se tiene la suficiente capacidad técnica para realizar transmisiones directas al público en todo el mundo. Vale decir, una señal totalmente transnacional y libre de filtraciones. Las transmisiones no respetan los mercados existentes, las fronteras nacionales, los derechos de propiedad intelectual y artística o la estructura establecida de radiodifusión política y de poder.

En efecto, el SRD creará la máxima proximidad entre puntos remotos. La economía de los satélites de comunicaciones no es sensible a la distancia: trasciende a la geografía. El coste de transmisión consiste en el envío de la señal hacia arriba y abajo, y no en la extensión geográfica.

Los satélites de radiodifusión directa, aun tomando en cuenta las diferencias culturales, la barrera del idioma y el alto costo del ingreso al mismo, permiten una invasión sin cortapisas a los mercados internos tradicionales. Con un SRD todos somos vecinos de todos, con todo lo que implica: enriquecerse, influirse e irritarse mutuamente.

\section{Biblioteca de Letras}

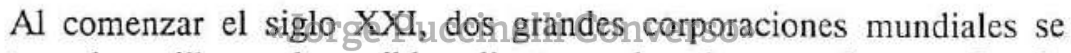
disputan a los millones de posibles clientes en los cinco continentes. Son la Hughes Electronics Corp. de la General Motors, empresa norteamericana, y la News Corp., el conglomerado que lidera el magnate australiano Rupert Murdoch.

DirectTV, el servicio de transmisión de Hughes, tendrá para comienzos del 2001 cerca de 10 millones de suscriptores tan sólo en Estados Unidos, una cifra considerablemente superior al menos de un millón que tenía hace cinco años.

Esta situación, junto al hecho que los suscriptores de DirectTV están pagando más por mes que el promedio de los usuarios de la industria de televisión por cable o satélite, es lo que está atrayendo a las compañías que son contactadas por los banqueros de Hughes, ante una eventual venta de la empresa. 
DirectTV tiene una fuerte presencia en América Latina, donde su base de abonados ha aumentado un $68 \%$ en doce meses, a más de un millón de abonados. El servicio es suministrado por Galaxy Latin America, una compañía de la que $78 \%$ está en manos de Hughes Electronics y el restante $22 \%$ es del consorcio venezolano Cisneros Group Companies.

Precisamente, esta penetración en el mercado continental es lo que hace de DirectTV un blanco apetecible para News Corp., ya que no solamente se convertiría en el mayor proveedor de comunicaciones satelitales del mundo, sino que lograría beneficios financieros inmediatos en América Latina.

News Corp. ha estado construyendo durante la pasada década varios sistemas de satélites alrededor del mundo, y transmite una programación para múltiples canales en Gran Bretaña, Asia y América Latina. Pero a pesar de dos intentos previos, Murdoch no ha sido capaz de establecer una cabeza de playa en el negocio estadounidense de televisión por satélite.

\section{La Televisión de Alta Definición: calidad cinematográfica}

Pero, aún la señal de televisión, en el ámbito universal, muestra limitaciones evidentes, debido a las normas técnicas que existen.

Hay naciones qui tienentuna senafde-525-lineas y otras de 625 y las normas de color son 'trese NTCRin(notieamericana), Pal (anglo-germana)y SECAM (franco-rusa), con algunas modificaciones nacionales.

Sin „embargo, estas limitaciones prácticamente están a punto de ser superadas. La Unión Internacional de Telecomunicaciones de Ginebra (UIT) dio su respaldo a una recomendación de Estados Unidos y Japón para la adopción de nuevas normas de transmisiones.

La propuesta establece la creación de un sistema de alta definición con más de mil líneas en una pantalla de televisión. De ser adoptada esta propuesta la recepción televisiva sería de una calidad casi comparable a la de un filme de 35 milímetros y de cuatro a cinco veces el nivel de definición de los sistemas de televisión actuales, con 10 veces de mejora en la definición del color. Habrá una pantalla más ancha, parecida a las proporciones de las salas cinematográficas, y un sonido estereofónico completo. Sería, pues, una norma 
única a nivel mundial para el intercambio de programas entre todas las naciones del mundo.

Desde luego, su aplicación enfrentaría graves problemas económicos: las empresas tendrían que desmontar sus instalaciones y adquirir las nuevas, y los usuarios dejar fuera de uso sus actuales televisores y comprar los de la flamante tecnología.

Sin embargo, la Televisión de Alta Definición, cuya sigla en inglés es HDTV y TVAD en español, ha experimentado una radical modificación por el increíble adelanto tecnológico en el campo de la informática y la digitalización. Japón, que fue el primer país en desarrollar la Televisión de Alta Definición con una inversión de 10 mil millones de dólares, lo hizo utilizando la señal analógica o señal normal. Estados Unidos, no sólo la nación más poderosa sino el mejor mercado potencial, ha causado un golpe mortal a la hegemonía nipona al aprobar la señal digital, esto es el lenguaje binario de ceros y unos que rige en las computadoras.

Los experimentos realizađos demostraron que la señal digital no sólo era tan buena como la analógica desarrollada por los japoneses, sino que la supera en muchos aspectos complementarios, como facilidad operativa y menores costos. Estados Unidos y Europa rápidamente se han comprometido con el estándar digital, aislando a Japón.

Para precisar lo que es la television de aita definición hay que recordar algunas características de la televisión clásica y del cine. La televisión, tal y como la utilizamos hoy, es un sistema electrónico de reproducción de imágenes que utiliza 625 líneas en Europa y 525 tanto en América como en Asia. Cada línea está compuesta por una serie de puntos llamados pixeles. La definición de una imagen de televisión se expresa por el número de puntos por línea. En el mejor de los casos éste es de 750, es decir, el número de puntos por imagen varía entre 400 mil y 500 mil.

El formato de la imagen de televisión, consistente en la relación entre altura y el ancho, ha sido internacionalmente normalizado en cuatro tercios (cuatro de ancho y tres de alto), debido a la utilización de tubos circulares para captar la luz en las cámaras. 
En cuanto al cine, hay que recordar simplemente que su definición es de tres millones de puntos por imagen y que su formato es de $5 / 3$ (1.66). Es decir 5 de ancho y 3 de altura.

Los promotores de la HDTV o TVAD buscan una imagen cuyas características de resolución y formato se asemeje a las de la imagen cinematográfica.

Los diferentes sistemas propuestos cuentan con 1250 líneas en Europa, 1125 en Japón y 1050 en Estados Unidos.

El número de puntos por línea es de unos 2,000, lo que da una imagen de dos millones de puntos. En todos los sistemas el formato de las imágenes es de $16 / 9$ (una pantalla alargada de 16 de ancho y 9 de alto), cercano a los $5 / 3$ del cinematográfico, valor al cual el ojo humano se adapta mucho mejor.

\begin{tabular}{|c|c|c|c|}
\cline { 2 - 4 } \multicolumn{1}{c|}{} & TV clásica & Cine & TVAD \\
\hline $\begin{array}{c}\text { Definición } \\
\text { Puntos/Imagen }\end{array}$ & 900,000 & 3 & 5 \\
\hline Formato & $4 / 3$ & $5 / 3$ & $2 ’ 00,000$ \\
\hline
\end{tabular}

El contexto en el que se ha desarrollado la TVDA comprende variables tanto económicas como tecnológicas. "Jorge Puccinelli Converso"

Desde hace diez años, los japoneses han monopolizado la fabricación de grabadores de video (tanto para el uso profesional como para el de aficionados) y ocupan una posición dominante en materia de producción de cámaras. Ninguna firma norteamericana produce cámaras y la europea Thomson utiliza piezas Sony para la fabricación de las suyas. Los japoneses están también a la cabeza de la fabricación de componentes electrónicos.

Cada vez más, en la producción de televisión como en la producción sonora o la transmisión, los sistemas numéricos basados en la utilización en dos estados, cero y uno, reemplazan a los analógicos basados en la propagación de ondas eléctricas que varían constantemente.

En los sistemas de televisión, prácticamente todos los elementos de la cadena de tratamiento de la señal pueden ser digitales, sólo las cámaras no 
lo son todavía totalmente. Pero la ola de lo digital avanza rápidamente y tanto los ingenieros como los técnicos están de acuerdo en que ese sistema reemplazará definitivamente a los anteriores. El problema está en saber "cuándo". Es importante recordar esto pues el porvenir de la TVAD se juega más sobre ese "cuándo" que sobre la rivalidad Europa-Japón, de la que tanto se ha hablado.

Hay que indicar que en EE.UU. la Comisión Federal de Comunicaciones puso a correr a las compañías fabricantes de televisores al anunciar recientemente que el Congreso debería hacer obligatorio el uso de televisores digitales para el 2003. El plazo vigente para la adopción del formato digital vence el 2006. Al promediar el 2000, cerca de 150 estaciones de TV estadounidenses ya emitían señales digitales, pero no existe ninguna TV inferior a 34 pulgadas que sea capaz de recibirlas sin la ayuda de un aparato adicional.

Los canales y los fabricantes se preguntan qué debe venir primero. Las emisoras dicen que los usuarios deben tener equipos digitales antes de cesar las transmisiones convencionales. Los fabricantes, por su parte, afirman que los televidentes necesitan algo que ver en sus canales digitales, antes de comprar equipos de este género.

Y todo es porque la TVAD o HDTV debe ser vista por el telespectador en su domicilio. Para tal efecto, debe viajar por cable o por vía hertziana. Pero la riqueza en puntos de su imagen requiere mucho espacio en los canales hertzianos. Para reducir el espacio cocupado, fodd los sistemas tratan de bajar el caudal de transmisión, ya sea disminuyendo el número de puntos emitidos, como es el caso del sistema japonés Muse y del europeo HD MAC, ya sea transformando físicamente la señal para ganar espacio (sistemas americano). En todos los casos, los microprocesadores del receptor vuelven a calcular la imagen final para restituirle toda su definición.

La TVDA es una tecnología de punta que requiere inversiones considerables para fabricar un producto caro y dirigido a un número reducido de consumidores, a nivel mundial. Sólo las potencias económicas con grandes posibilidades de inversión y que cuentan con un mercado suficiente pueden lanzarse a la aventura.

Francia no poseía los medios para hacerlo sola, razón que la condujo a proponer un proyecto común a escala europea denominado "Eureka". La 
exUnión Soviética de Gorbachov observaba los esfuerzos europeos sin hacer nada en ese campo. Así, el triángulo quedó conformado por Europa, Japón y los Estados Unidos.

1. El avance japonés. Desde fines de los años sesenta, el Japón se interesó por la TVAD. En 1972, los investigadores japoneses propusieron al Centro Consultivo de Relaciones Internacionales de Radiocomunicación (CCIR) un proyecto de estudio de ese nuevo medio. Catorce años más tarde el proyecto presentado por la Nippon Hoso Kyokai (NHK) -televisión estatal japonesa-, y apoyada por la Sony, se convirtió en una norma de televisión a la que se llamó "Muse". Los japoneses solicitaron entonces que dicha norma fuese adoptada por toda por toda la comunidad internacional. Pero cuando los norteamericanos estaban dispuestos a aceptar, los europeos solicitaron al CCIR que la decisión se pospusiera hasta 1990. Sin embargo, los japoneses no cesaron de trabajar ni de invertir en su proyecto. Han fabricado material de producción TVAD y poseen, desde 1991, la primera cadena de esta modalidad.

2. La respuesta europea. Después de haber bloqueado el predominio japonés, los europeos comenzaron a movilizarse para preparar su propio sistema de TVAD. Este se apoya en investigaciones precedentes y especialmente en los trabajos franceses sobre el sistema de transmisión D2 MAC Paquet, unhíbrido analógico-numéricoque da imágenes y sonidos de mejor calidad que los sistemas analógicos clásicos (PAL, SECAM, NTSC). Los constructores europeos (Thomson, Phillips) y los organismos estatales (como France Telecom) se unieron en el proyecto europeo Eureka 95, con miras a los Juegos Olímpicos de Albertville y de Barcelona.

3. Los norteamericanos. No pudiendo apoyarse en las firmas productoras de equipos para el actual sistema de televisión, los norteamericanos decidieron concentrar su investigación en los sistemas íntegramente digitales. La batalla euro-nipona les ha dejado un campo libre.

Como se ha señalado, la opinión general considera que la TVAD se desarrolla más lentamente de lo previsto. Esto se explica por varias razones: los aparatos de televisión con calidad de alta definición resultan todavía muy costosos (alrededor de 4 mil dólares); los problemas de transmisión no están 
todavía totalmente resueltos; y la producción en alta definición cuesta aproximadamente el doble de la actual.

Todo parece indicar que el sistema digital desarrollado por los norteamericanos se va a imponer. Sin embargo, el estado de entrelazamiento de las economías (presencia de empresas europeas y japonesas en los proyectos estadounidenses) permite decir que si el sistema enteramente digital se adopta como norma mundial de TVAD, ello no implicará una victoria de la tecnología de los Estados Unidos, sino una elección en el marco de la concurrencia simbiótica que caracteriza al mundo audiovisual de fines del siglo XX.

\section{BIBLIOGRAFÍA}

BECK, A.H.W.

1971

Palabras y ondas. Madrid, Guadarrama,

BITTNER, John

1986

Communication. New Jersey, Prentice-Hall.

BORDEN, George Biblioteca de Letras

1982

La comunicación humana. Buenos Aires, El Ateneo.

CEBRIÁN, Juan Luis

1998

La red. Madrid, Taurus.

DWIGGINS, Don

1972

Historia de los satélites de comunicaciones. México, Troquel.

FERNÁNDEZ HERRERA, Luis Ángel

1997

En.red.ando. Madrid, Ediciones Grupo Zeta.

FULLER, Jack

1997

News Values. Ideas for un Information Age. Chicago, University of Chicago Press 
HOLLAND, Patricia

1997

Television Handbook. London, Routledge.

KALBA BOWEN ASSOCIATES

1980

Direct Broadcast Satellites: Preliminary Assessment of Prospects and Policy Issues. Washington, D.C., National Association of Broadcasters.

MAJO, Juan

1998

Chips, cables y poder: Barcelona, Planeta.

MAY, Matheus

1980

The Birth of Mass Culture and the Motion Picture Industry. New York, Oxford University Press.

MCLUHAN, Marshal

1963

La aldea global. México, Editorial Gedisa.

RIVERS, William

1973

Responsabilidad y comunicación de masas. Buenos Aires, Troquel.

SARTORI, Giovanni 1999

Homo videns. Buenos Aires, Taurus. "Jorge Puccinelli Converso"

SILBERGLED, Michael

1999

Digital Television. New York, Miller Freeman.

TOFLER, Alvin

1970

Future Shock. New York, Random House.

WELLS, Robert

1970

Las maravillas de la comunicación electrónica. Buenos Aires, Plaza \& Janés.

WILLIAMS, Federick

1992

The Communications Revolution. Beverly Hills, California, Sage Publications. 
REVISTAS

TV Technology. IMAS Publishing. EE.UU. Publicaciones quincenales.

On The Verge. National Association of Broadcasters. Washington, 1998.

Videography. New York, Miller Freeman PSN Inc. Publicación mensual.

Government Video. New York, Miller Freeman PSN Inc. Publicación bimensual.

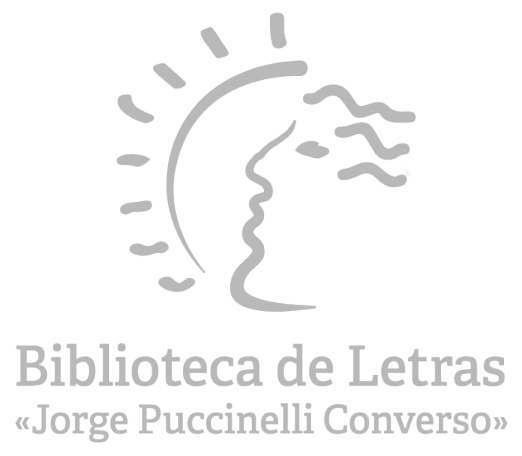

